\title{
A Rare Cause of Dystonia: Spinal Meningioma
}

\author{
Distoninin Nadir Bir Nedeni: Spinal Menenjiom
}

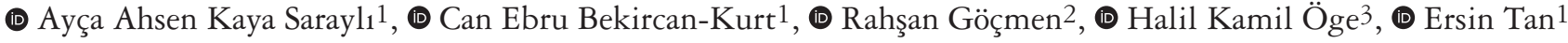

${ }^{1}$ Hacettepe University Faculty of Medicine, Department of Neurology, Ankara, Turkey

2Hacettepe University Faculty of Medicine, Department of Radiology, Ankara, Turkey

3Hacettepe University Faculty of Medicine, Department of Neurosurgery, Ankara, Turkey

Keywords: Spinal meningioma, dystonia, diffusion tensor imaging

Anahtar Kelimeler: Spinal menenjiom, distoni, difüzyon tensor görüntüleme

\section{Dear editor,}

A 58-year-old female referred to our department with progressive clumsiness, ataxia, a "weird posture", rigidity, and contractions in all extremities for 3 months. Neurologic examination depicted bilateral pyramidal findings without motor deficits including bulbar or respiratory weakness and impaired vibration and position sensation until the wrists and knee. Moreover, the patient hyperextended her neck while walking and she had a dystonic posture in her left hand. Cervical magnetic resonance imaging showed an extramedullary, homogenously enhancing $2.8 \times 1 \times 1.5 \mathrm{~cm}$ mass at the $\mathrm{C} 1-2$ level that displaced the spinal cord to the right and posterior causing myelopathy (Figure 1A, B, C, D). Diffusion tensor imaging-fiber tractography map demonstrated the compression of bilateral corticospinal tracts (Figure 1E). The mass was completely resected (Figure 1F, G) and the pathologic findings were compatible with World Health Organization grade 1 meningioma (1). The sensory deficits and dystonic posture disappeared four months after surgery.

It is generally assumed that dystonia occurs due to network disorders involving the basal ganglia, thalamus, brainstem, cortex and cerebellum. Disorders in other motor and sensory pathways may cause dystonic or compensatory postures that may also be called "pseudodystonia" (2). Loss of proprioception sensation is the main cause of dystonia associated with deafferentation. Although the underlying mechanism has not been fully

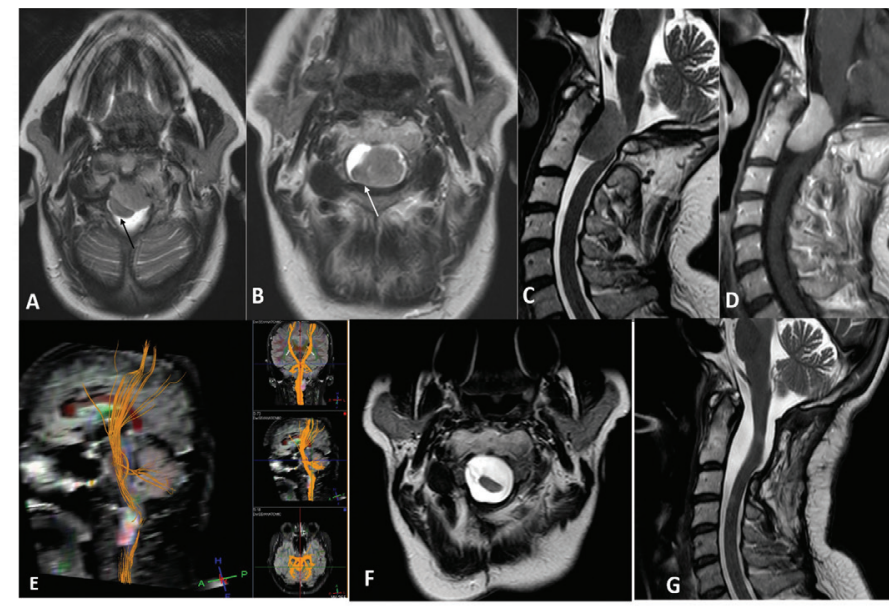

Figure 1. Cervical spinal MRI. Axial (A, B), sagittal (C) T2W images and postcontrast T1W image (D) show an extramedullary mass enhancing homogeneously at the C1-2 level. Note the marked cord compression. Diffusion tensor imaging-fiber tractography map (E) demonstrates compression of bilateral corticospinal tracts. Postoperative axial (F) and sagittal (G) T2W images reveal gross-total resection of the dural mass and resolution of the cord compression

MRI: Magnetic resonance imaging

Address for Correspondence/Yazışma Adresi: Can Ebru Bekircan-Kurt MD, Hacettepe University Faculty of Medicine, Department of Neurology, Ankara, Turkey

Phone: +90 3123051741 E-mail: canebru@yahoo.co.uk ORCID: orcid.org/0000-0003-2355-6979

Received/Geliş Tarihi: 19.06.2020 Accepted/Kabul Tarihi: 09.04.2021

${ }^{\circ}$ Copyright 2021 by Turkish Neurological Society

Turkish Journal of Neurology published by Galenos Publishing House. 
elucidated, it is widely accepted that insufficient or abnormal sensory input impairs motor and sensory integration and results in dystonia (3). This phenomenon is generally reported in patients with subacute combined degeneration, multiple sclerosis or polyradiculoneuropathy (2). However, spinal meningiomas, which are slow-growing tumors, are not considered a cause of dystonia and patients are generally diagnosed when gait ataxia or neurologic deficits appear due to severe spinal cord compression (4). Here, the meningioma compressed the corticospinal tract and displaced the spinal cord to the right and posterior, which caused posterior column dysfunction. Also, the joint position sensation loss resulted in dystonic posture in the upper extremity. This case demonstrates the crucial role of proprioceptive inputs in limb coordination balance control, and motor skills (5).

\section{Ethics}

Informed Consent: Written consent has been obtained. Peer-review: Externally peer-reviewed.

\section{Authorship Contributions}

Surgical and Medical Practices: H.K.Ö., E.T., A.A.K.S., Concept: E.T., C.E.B.K., R.G., Design: C.E.B.K., R.G., E.T.,
Data Collection or Processing: A.A.K.S., R.G., Analysis or Interpretation: C.E.B.K., R.G., E.T., Literature Search: C.E.B.K., A.A.K.S., Writing: A.A.K.S., C.E.B.K.

Conflict of Interest: No conflict of interest was declared by the authors.

Financial Disclosure: The authors declared that this study received no financial support.

\section{References}

1. Perry A, Stafford SL, Scheithauer BW, Suman VJ, Lohse CM. Meningioma grading: an analysis of histologic parameters. Am J Surg Pathol 1997;21:1455-1465.

2. Berlot R, Bhatia KP, Kojovic M. Pseudodystonia: a new perspective on an old phenomenon. Parkinsonism Relat Disord 2019;62:44-50.

3. Hallett M. Is dystonia a sensory disorder? Ann Neurol 1995;38:139-140.

4. Klekamp J, Samii M. Surgical results for spinal meningiomas. Surg Neurol 1999;52:552-562.

5. Hillier S, Immink M, Thewlis D. Assessing Proprioception: A Systematic Review of Possibilities. Neurorehabil Neural Repair 2015;29:933-949. 